\title{
0839 Characteristics of Dual Species Candida Biofilms on Denture Acrylic Surfaces
}

Z.M. THEI N, Y.H. SAMARANAYAKE, and L.P. SAMARANAYAKE, University of Hong Kong, Hong Kong, HKSAR, Hong Kong

Fungal biofilms contribute to the pathogenesis of oral candidiasis, some $15 \%$ of which may be due to dual species infection. Despite extensive studies on single species fungal biofilms on denture acrylic surfaces, the characteristics of dual species biofilms (DSB) are unknown. Objectives: To examine interactions in DSB of C. albicans and C. krusei on denture acrylic. Methods: Two isolates each of $\mathrm{C}$. albicans $\left(\mathrm{Ca}_{h} ; \mathrm{Ca}_{1}\right)$ and $\mathrm{C}$. krusei $\left(\mathrm{Ck}_{h} ; \mathrm{Ck}_{l}\right)$, with high and low biofilm forming ability were used. They were grown in YNB+100 mM glucose and incubated aerobically at $37^{\circ} \mathrm{C}$ and growth quantified by CFU counts of the resultant biofilm. We determined a) the cell profile of DSB comprising each pair of Candida species of a total of four combination pairs ( $\mathrm{Ca}_{h} \vee \mathrm{Ck}_{h}$; $\mathrm{Ca}_{h} \vee \mathrm{Ck}_{l}$; $\left.\mathrm{Ca}_{1} \vee \mathrm{Ck}_{h} ; \mathrm{Ca}_{1} \vee \mathrm{Ck}_{l}\right)$ after $\left.12 \mathrm{~h} ., \mathrm{b}\right)$ the effect of a constant concentration of $\mathrm{Ca}_{h}\left(1 \times 10^{\text {cell }} \mathrm{s} / \mathrm{ml}\right)$ with varying concentrations of $\mathrm{Ck}_{\mathrm{h}}$ (103-10 cells/ml) on DSB development and, c) the effect of saliva on the growth of the DSB. Results: 1) DSB exhibited a lower level of biofilm cell volume after $9 \mathrm{~h}$ and $12 \mathrm{~h}$ in comparison to single species biofilms ( $P<0.05$ ). 2) C. albicans ( 10 cells/ml) co-incubated with varying concentrations of $C$. krusei was inhibited at high concentrations of $C$. krusei (10-10 cells/ml) after $9 \mathrm{~h}(\mathrm{P}<0.05)$. 3) Only mono-species (control) C. krusei biofilm formation was affected by either saliva pretreated acrylic or the addition of saliva to the incubating medium $(P<0.05)$. Conclusion: Our data suggest that the competitive interaction of fungal species may be important in DSB formation on acrylic surfaces and human saliva appear to further modulate this process. (Supported by the Research Grant Council and the Committee of Research and Conference grants, University of Hong Kong, HKSAR).

Seq \#72 - Candida

11:00 AM-12:00 PM, Thursday, 29 June 2006 Brisbane Convention \& Exhibition Centre Exhibit Hall 1

Back to the Microbiology / I mmunology and I nfection Control Program Back to the IADR General Session \& Exhibition (J une 28 - July 1, 2006) 